of something in these cows competent to produce scarlatina in persons consuming their milk, and the inquiry was narrowed to determining what this was. All comparison with former experiences was for the present left out of consideration, the investigation proceeding strictly on the circumstantial evidence obtained and obtainable. A consideration of all that had gone before, and the absence of any alternative, led to the provisional adoption at this point of a theory of disease in the cows, and the probability was that this was an infectious disease, communicable from cow to cow, a disease, moreover, the existence of which was compatible with the animal affected feeding well, and milking abundantly.

The discovery of vesicles and ulcers on the teats and udders of cows in the large shed soon followed; the first to show the disease was one of the Derbyshire cows, the second one from Oxfordshire. After this the matter passed into Dr. Klein's hands; but with his report we have nothing to do here. A painful incident soon gave $\mathrm{Mr}$. Power ample corroboration of the result which he had reached. The Marylebone dealer returned on the farmer's hands, on December I5, all his milk from the larger shed, and this was destroyed by pouring it into a pit dug on his land. The news of the destruction of milk spread among some of the poor people of Hendon, and some of them succeeded by the favour of friends amongst the cowmen in obtaining some of it on December 16. By the 2oth scarlatina made its appearance amongst half-a-dozen of the families thus supplied. Conversely in South Marylebone about Christmas, when these Hendon families were falling ill, the disease ceased almost suddenly, and there were no fresh attacks, except such as were referable to infection from previous sufferers.

A thorough examination of all the cows showed that the disease had spread to every one of the three sheds, and the farmer was accordingly advised to seek out every cow then or afterwards affected with sore teats or udder, or any other ailment, to isolate her and keep all her milk out of the business, and prevent cowmen employed about the sound cows from attending the infected ones. These precautions were taken from January I, and were barely in time to prevent an alarming increase of scarlatina in all the districts served from Hendon, including St. John's Wood, where the appearance of scarlatina corresponded to a nicety with the appearance of the cow-disease in the animals in the small shed. The milk from the Hendon farm was ultimately given up by all the dealers concerned, with the result that scarlatina has disappeared from amongst the customers of the dealers here referred to in Marylebone, St. Pancras, Hampstead, and St. John's Wood. The work of demonstrating the nature of the cow-disease, and its connection with human scarlatina was not Mr. Power's, and from him the matter passed on to Dr. Klein. The former had succeeded in gathering up and connecting the scattered links of a chain of presumptive evidence against certain cows so strong as to be unassailable ; and he had done this by the exercise of patience, sagacity, and acuteness which would have done credit to a great criminal lawyer weaving the web of circumstantial evidence around an unusually cunning forger or murderer.

\section{THE ORIGIN OF VARIETIES}

T'HE publication in the three last numbers of NATURE, by Mr. Romanes, of very important papers, ${ }^{1}$ induces me to send the following lines as a contribution to the discussion upon them that is sure to ensue. $\mathrm{He}$ ascribes the origin of varieties to peculiarities in the reproductive system of certain individuals, which render them more or less sterile to other members of the common stock, while they remain fertile among themselves.

I I write from abroad, and have not yet seen the original memoir pub. lished by the Linnean Society.
I also have a theory which, while it differs much from that of Mr. Romanes, runs on curiously parallel lines to it, and was prompted by the same keen sense of an inadequacy in the theory of Natural Selection to account for the origin of varieties. I should not have published my views until they had been farmore matured than they are had not the present occasion arisen.

It has long seemed to me that the primary characteristic of a variety resides in the fact that the individuals who compose it do not, as a rule, care to mate with those who are outside their pale, but form through their own sexual inclinations a caste by themselves. Consequently that each incipient variety is probably rounded off from among the parent stock by means of peculiarities of sexual instinct, which prompt what anthropologists call endogamy (or marriage within the tribe or caste), and which check exogamy (or marriage outside of it). If a variety should arise in the way supposed by Mr. Romanes, merely because its members were more or less infertile with others sprung from the same stock, we should find numerous cases in which members of the variety consorted with outsiders. These unions might be sterile, but they would occur all the same, supposing of course the period of mating to have remained unchanged. Again, we should find many hybrids in the wild state, between varieties that were capable of producing them when mated artificially. But we hardly ever observe pairings between animals of different varieties when living at large in the same or contiguous districts, and we hardly ever meet with hybrids that testify to the existence of unobserved pairings. Therefore it seems to me that the hypothesis of Mr. Romanes would in these cases fail, while that which I have submitted would stand.

The same line of argument applies to plants, if we substitute the selective appetites of the insects which carry the pollen, for the selective sexual instincts of animals. Both of these, it will be remembered, are mainly associated with the senses of smell and sight. If insects visited promiscuously the flowers of a variety and those of the parent stock, then-supposing the organs of reproduction and the period of flowering to be alike in both, and that hybrids between them could be produced by artificial cross-fertilisation-we should expect to find hybrids in abundance whenever members of the variety and those of the original stock occupied the same or closely contiguous districts. It is hard to account for our not doing so, except on the supposition that insects feel a repugnance to visiting the plants interchangeably.

No theme is more trite than that of the sexual instinct. It forms the main topic of each of the many hundred (I believe about 800 ) novels annually published in England alone, and of most of the still more numerous poems, yet one of its main peculiarities has never, so far as I know, been clearly set forth. It is the relation that exists between different degrees of unlikeness and different degrees of sexual attractiveness. A male is little attracted by a female who closely resembles him. The attraction is rapidly increased as the difference in any given respect between the male and female increases, but only up to a certain point. When this is passed, the attraction again wanes, until the zero of indifference is reached. When the diversity is still greater, the attractiveness becomes negative and passes into repugnance, such as most faircomplexioned men appear to feel towards negresses, and vice versâ. I have endeavoured to measure the amount of difference that gives rise to the maximum of attractiveness between men and women, both as regards eyecolour and stature, chiefly using the data contained in my collection of "Family Records," and have succeeded in doing so roughly and provisionally. To determine it thoroughly, and to lay down a curve of attractiveness in which the abscissæ shall be proportional to the amounts of difference, and the ordinates to the strength of attraction, would require fresh and special data that have 
yet to be collected and discussed, and about which I will not now speak. Suffice it to say that such inquiries as I have made confirm, so far as they go, the reasonable expectation that some more or less regular curve will be found to exist in respect to any given quality or group of qualities. Each individual would possess his own characteristic curve, but the average of the tastes of many individuals would, as all statistical experience justifies us in believing, afford fairly constant data. These would enable us to argue out the hypothesis I have submitted, with mathematical precision; at all events, with much more closeness of reasoning than is now possible. But this much may even now be averred: (I) That the existence of a law of sexual selection such as I have described, is probable ; $(2)$ if it exists, it would have a powerful influence in rounding off any incipient variety that differed notably in any one particular or in any group of particulars from the parent stock; (3) it would be favourable to the vigour of the variety, after it was once fairly started, by checking too close interbreeding.

It must be borne in mind that differences overlooked by ourselves, who are singularly deficient in the sense of smell, and who are hardly able to distinguish without scrutiny even the sexes of some animals, may seem very considerable to the animals themselves. Also that the only differences that we are able to recognise between two varieties may connote a host of unseen differences, whose aggregate would amply suffice to erect a barrier of sexual indifference or even repugnance between their members.

August 23

FRANCIS GALTON

\section{NOTES}

THE Local Committee of the Birmingham meeting of the British Association has issued a descriptive programme of the excursions which have been arranged for Saturday, September 4, and Thursday, September 9. The programme covers I20 pages, and has been compiled by several specialists with the greatest care. There are twenty-seven excursions in all, besides a geological excursion to the Lower Palæozoic district of Shropshire. This excursion will last six days, from September 9 to September 15. Prof. Lapworth will take the leadership.

THE French Association for the Advancement of Science has concluded its annual meeting at Nancy, after having resolved that the 1888 session will be held in Oran, Algeria; Col. Laussedat has been elected President for that meeting. The 1887 session will be held in Toulouse, as decided at the last meeting.

AT the Buffalo meeting of the American Association it was proposed to devote especial attention to the study and discussion of the interesting phenomena of the Niagara Falls and the gorge below. On Friday, August 20, one or more preliminary papers of an expository and suggestive nature were to be given, intended to prepare the way for a short field-study of the Falls and the gorge, which occupied Saturday. Monday forenoon would be devoted to the discussion of the gorge and the problems to which it gives rise. A new survey of the Falls has been arranged for, so that a considerable addition to the data for the computation of the rate of recession will be at command, and it is expected that new observations in other important lines bearing upon the chronology of the gorge will be presented, and will throw fresh light upon the history of the formation and recession of the Falls, and upon the utility or untrustworthiness of the gorge as a geological measure of time.

WE learn that the Lick Trustees-after a most thorough discussion of the various plans and specifications submitted for the mounting of the 36 -inch refractor of the Lick Observatory and for the steel dome to cover the same, and with a special con- sideration of the element of time, which circumstances now make one of vital interest to the work-have let the contract for the former to Warner and Swasey of Cleveland, Ohio, for 42,000 dols., and the contract for the latter to the Union IronWorks of San Francisco for 56,850 dols. The Trustees acknow ledge the very prompt and courteous manner in which Mr. Grubb has responded to their invitation, and the very great disadvantage to which he has been put by the remote situation of his works from California, \&c. The President of the Trustees has stated that he believes that Mr. Grubb's idea of an elevating floor in principle offers the best solution yet submitted of the very difficult problem of a convenient chair for the observer with so large a telescope. The method of elevating the floor will have to be adapted to the peculiar circumstances of the site of the Lick Observatory, and the means to be commanded there with its very limited water-supply. This subject is now being carefully studied, and so far the only apparent obstacle to the adoption of Mr. Grubb's plan is the question of cost.

WE have to record the death, at Tomsk, of Alexander Krapotkin, on August 6, at the age of forty-five years. M. Krapotkin had done some good work for science in Russia. He had translated into Russian Mr. Herbert Spencer's "Principles of Biology," and Clerk-Maxwell's " Theory of Heat," and for several years contributed to Russian periodicals reviews of the progress of physical astronomy, much valued by Russian astronomers. In 1874 M. Krapotkin was exiled to Minusinsk in East Siberia, and there he helped Dr. Martianoff to organise a local museum ; and for several years carried on meteorological observations, which were printed by the Kazan Society of Naturalists. His most important work, however, was a critical investigation of all our present knowledge of the stellar systems and constitution of stellar groups. Every known source in every European language was ransacked for data, though the difficulties he encountered in his peculiar position prevented him from bringing his work down to a later date than 1879 . He hoped to complete the work, and publish it, after his expected liberation in September. His untimely death has put an end to this hope.

We have received the third number of the fournal of a Society recently founded in Bombay, called the Natural History Society of Bombay, which, though it is young, appears to have abundant vitality. There are already several learned societies in India and Ceylon, all of which appear to be very successful ; but the field is so vast and varied, and the number of men, servants of the. Crown and others, capable of doing good work is so great, that it is impossible to have too many of these associations, and accordingly we welcome the new Society, and are glad to notice the energy it displays. In the number of the Fournal before us, Capt. Becher describes the life (mainly the bird-life) of a Sind lake, Manchar, near the Indus ; "A member of the Society" similarly compiles some notes on animal life in the rivers of British Deccan and Kandesh. Mr. Sterndale, one of the editors, has a paper, with illustrations, on abnormalities in the horns of ruminants, in which he expresses the opinion that there is neither persistence nor transmission in the abnormalities of antlered deer, but that they must be persistent in the case of hollow-horned ruminants, and that in the latter case the adage is true: "As the twig is bent, so is the tree inclined." Mr. Aitken, the second editor, publishes a list of the Bombay butterflies in the Society's collection, with notes. The collection appears to be far from complete in any direction. Dr. Kirtikar describes a new species of Alga (Conferva thermalis Birdwoodii), discovered among the hot-water Algæ in the hot springs of Vajrabai. There are, in conclusion, various zoological and botanical notes, and a list of presentations to the Society, which we notice in order to mention that they appear to be of great number and variety. One present is a collection of 105 